\title{
DE CASTELLNOU A TLEMCEN: LA CRÓNICA DE SHEM TOV DE TUDELA DE NAVARRA
}

\author{
Eleazar GUTWIRTH \\ Israel
}

La fuente más importante y más rica en datos acerca de Shem Tov es su narrativa o crónica'. Por ella sabemos que era originario de Tudela. Viaja a Castellnou por problemas con la Inquisición. Allí tiene con sus hijos algún tipo de comercio/trabajo. A juzgar por una referencia en el texto sus ocupaciones podrían tener relación con textiles. Nos habla de cuatro hijos, dos mayores, [Isaac el primogenito y Samuel] y dos menores, [Josue y Ya'aqov]. La Inquisición de Valencia lo apresa y después de tres semanas logra huir. Se reúne con sus hijos y trata de ir a Tortosa para embarcarse. Desde ese momento todo es una serie de tentativas de embarque y una serie de persecuciones y encarcelamientos. En el camino a Tortosa se los reconoce como perseguidos por la Inquisición. Vuelven a mitad de camino, logran pasar desapercibidos por la ciudad de Valencia y llegan a Almería. Allí los apresan y logran ser puestos en libertad. La crónica describe sus percances en un constante movimiento: de Almería para

1 V. la transcripción en Ya'aqov Moshe Toledano «Mi-Kitve Yad» (Hebreo) HUCA V (1928) 403409 .

Utilizo el nombre que figura en la rúbrica de su obra Keter Shem Tov [posterior al colofón del prólogo a la misma]: «Shem tov ben Kevod Ha-Nadiv Rav Shemuel ben Jamil ha-megurash we-ha-metultal me'ir wa-em Tudela de Navarra". Me interesa subrayar que Shem Tov se refiere a Tudela a) como Tudela de Navarra; b) que la denomina "ciudad y madre» (cf. 2 Sam. 20/19) c) que lo hace mediante el uso de proposiciones en romance y no en hebreo. Acerca de la familia podemos deducir que el uso onomástico es de perpetuar los nombres Samuel y Shem Tov. Samuel es padre de Shem Tov y Shem Tov tiene un hijo denominado Samuel. En la década de los treinta del siglo XIV un Shem Tov Abenjamil aparece entre los documentos mencinados en Y.T. ASSIS The Jews in the Crown of Aragon 13281493 (Jerusalem 1995); en 29/11/1332 se menciona que Janto [e.d. Shem Tov] Abenjamil fue injuriado en presencia del almotacen de Teruel. 
Granada, Vélez Málaga, Carmona, Vélez Málaga, Granada y, ya en Marruecos, Safi, Sale, Alcázar, Fez y Tlemcen, donde escribe la crónica como prólogo a su comentario homelético al Pentateuco. Casi se sobreentiende que se trata de una persona instruida. Las muy frecuentes citas bíblicas son hábilmente utilizadas para crear una prosa hebraica con una flexibilidad no menos notable por tener análogos en escritos de otros judíos hispanos. La designación de la semana por referencia al pericopio litúrgico; la composición de sermones que predica en el Norte de África y el hecho de que se le elija para ese honor apenas llegado a la comunidad de Safi, y, finalmente, el hecho de que intente componer un comentario homelético basado en el Zohar, son todos datos relevantes para establecer su perfil intelectual. Puede que no sea por casualidad que la documentación externa parece asociarlo con la oficialidad de la aljama y los círculos del mundillo notarial de la comunidad judía de Tudela el jueves 20 de enero de $1480^{2}$. Ya la crónica demuestra que, paralelamente a su compenetración con las tendencias características de la cultura hispano-judía interna del momento en hebreo, hay toda una serie de indicios de otro tipo de inquietudes y rasgos culturales que dejan su marca a pesar de las convenciones de la composición de textos en hebrero. Así notaría, por ejemplo, su deseo de dejar constancia con relativa precisión de nombres de lugares y personas; sus observaciones sobre el entorno geográfico físico y medios de comunicación [referencias al mar, a ríos, a caravanas, a distancias de un lugar a otro]. Podría relacionarse con un posible y especial apego a la cultura en el romance de los judíos navarros, apego que se manifiesta en los términos romances que aparecen en las tempranas ordenanzas/estatutos en hebreo y en la redacción de ordenanzas en aljamiado romance después. Es un apego que explicaría la relativa riqueza de documentos aljamiados de Navarra que han sobrevivido. Es posible que los detalles de la onomástica, elemento tan importante en el pensamiento de Shem Tov, no sean enteramente fortuitos. La repetida preposición "de" en un texto hebreo y la insistencia de describir su origen como «de Tudela de Navarra» no se explican por un deseo de diferenciarse de los originarios de Tudela del Duero ${ }^{3}$, especialmente en textos dirigidos a un público judío de lectores de hebreo en el Norte de África que difícilmente hubieran pensado en Tudela del Duero. Más probable sería ver en este tipo de autodescripción un reflejo de la conciencia de entidad política que caracteriza al reino

2 J.L. LACAVE, «Importante hallazgo de documentos hebreos en Tudela» Sefarad XLIII (1983) 180-192; id. "Tres nuevas Ketubbot españolas» Proceedings Ninth WCJSt (Jerusalem 1986), pp. 9196. Se trata del documento hebreo № 8 del AMT, contrato matrimonial (en pergamino, $58 \times 60 \mathrm{~cm}$.) de Samuel bar Yom Tov Aspar y Buena hija de Ishaq Alcastiel y hermana de Salomon Alcastiel del 8 de Sebat de 5240. Según Lacave, Shem Tov ben Jamil pertenecía a una familia de raigambre tudelana y uno de sus antepasados, Hayyim figura entre los confirmantes de los estatutos de la aljama tudelana en el siglo XIV. Puede que sea de cierto interés notar la resonancia valenciana del nombre de la novia [Alcastiel] en el contrato matrimonial que firma Shem Tov cuya crónica lo relaciona con Valencia. Ver también el documento № 26 del Catálogo de la exposición Documentos hebreos en los archivos navarros (1287-1486) (Texto de J.L. Lacave) (Tudela 1998), p. 32.

3 Agradezco al Prof. J. Carrasco su amable sugerencia al respecto. V. también B. LEROY Le royaume de Navarre a la fin du Moyen Agel (Aldershot 1990), XVI. 
de Navarra en la época de [por ejemplo] los acuerdos comerciales «mercantilistas» con Castilla, época un poco anterior al pensamiento acerca de como incorporar Navarra al Reino de Castilla-Aragón; época en que se distingue entre judíos "nativos» de Navarra y judíos «extranjeros».

El relato de exilio en hebrero se Shem Tov de Tudela de Navarra no parece haber llamado la atención de los estudiosos hasta hace poco. En 1936 Fritz Baer le dedicaba dos palabras [incluyendo a Shem Tov entre einzelne nachzuegler] y en 1945 su Toldot ni lo mencionaba. Esta falta de atención no se puede imputar de ningún modo a una intrínsice falta de interés. Al contrario, entre las narrativas de primera mano del exilio es una de las más evidentemente interesantes. Posiblemente por este interés se notan recientemente ciertas tentativas de prestarle más atención. Así en 1981 se procuró analizar un tema de esta narrativa, en concreto la actitud hacia los musulmanes, dentro del contexto más amplio de las actitudes hispano-judías hacia los musulmanes en el siglo $\mathrm{XV}^{4}$.

En el caso de Shem Tov es evidente que el movimiento, el viaje es uno de los factores de coherencia en la organización de los datos. La crónica comienza con un viaje [a Castellnou] y continúa con toda una serie de viajes. Si fuese menos trágico, se podría delinear como un intento de construir un viaje de aventuras o de peripecias en hebrero cuatrocentista. Hoy en día sabemos que aunque el fenómeno cultural que significa el libro de viajes de Benjamín de Tudela no se repite en la baja edad media hispano-judía, la inversión creativa en textos en los cuales se elabora la noción del viaje, ya sea verdadero o ficticio, en hebreo, tiene cierta tradición en la baja edad media. Anque la comparación entre cierto tipo de crónicas [especialmente del siglo XVI] y los viajes de caballería no es inusitada, el viaje de aventuras de Shem Tov de Tudela de Navarra tiene afinidades sólo superficiales con viajes de aventuras en el romance. Aun dentro de la prosa hispano-hebraica bajo medieval las analogías con los viajes de la prosa rimada, tal cual Ahituv we-Salmon, no son decisivas. Es cierto que hay ya una tradición, más rica de lo que se solía creer, dentro de la cual se pueden componer relatos de viajes y viajeros en prosa hebraica en la baja edad media. Se ha estudiado recientemente con referencia a Yehudah ben Shelomoh en el siglo XIII; a Joseph ben Elezar en el XIV, y, ya en el siglo XV, a Da Piera, a Ibn Polia, ibn Habib y el prólogo al Maarekhet Ha-Elohut ${ }^{5}$.

Quisiera, sí, subrayar un elemento de coherencia más en la narrativa de Shem Tov de Tudela de Navarra que ya mencioné en ese estudio, es decir, la construcción tex-

4 Fritz BAER, Die juden im Christlischen Spanien (Berlin 1936); E. GUTWIRTH «Hispano-Jewish Attitudes to the Moors in the Fifteenth Century" ponencia al Congreso de la British Association for Jewish Studies, School of Oriental and African Studies, 1981. Publicada luego en Sefarad XLIX (1989), 237-262.

5 E. GUTWIRTH, "Viajes y viajeros hispanojudios en la baja edad media" en Viajes y viajeros en la España medieval (ed. P.L. Huerta et al.) (Palencia: Centro de Estudios del Románico, 1998), 293308. Sobre la elaboración temática del viaje ver también id., "Leer a Bonafed en su entorno» en $L a$ sociedad medieval a través de la literatura hispano-judia [ed. R. Izquierdo Benito y A. Sáenz Badillos] (Cuenca 1998), 341-357. 
tual o literaria de la subjetividad. En efecto, se puede argumentar que el elemento autobiográfico constituye una vértebra de la crónica de Shem Tov. Shem Tov de Tudela de Navarra escribe en hebreo, en primera persona, un relato autobiográfico y, por lo tanto, se puede argumentar que tiene raíces en una serie de tradiciones anteriores similares como los relatos ficticios de la maqama, a veces en primera persona, pero también tiene raíces más evidentes en la escritura no ficticia. De esta última se puede destacar la retórica del prólogo hebraico en general y en particular el accesus en textos hebraicos desde ibn Tibbon en adelante. De todos modos estos antecedentes no son los únicos factores en el notable auge de la autobiografía hebraica en el siglo XV. Su contexto, me gustaría argumentar, está en la construcción del sujeto en textos hebraicos de judíos ibéricos del siglo XV como ser los párrafos relevantes en las obras de Isaac Caro o de don Ishaq Abravanel por no mencionar a ibn Hayyat o ibn Farag'. Pero hay además un contexto cultural europeo y peninsular más amplio. Las 58 biografías en la obra de Pérez de Guzmán y de Pulgar son, creo, un dato importante a la hora de reconstruir el contexto cultural de autobiografías hispano-judías contemporáneas de Shem Tov de Tudela ${ }^{6}$.

Junto al componente de la representación del viaje y al componente de la representación del sujeto, o lo que se denomina "self fashioning", hay otro componente que crea la coherencia de esta narrativa y que puede ser útil para explicar, en parte, sus prioridades y silencios. Me refiero a las afinidades tonales o modales con lo que se puede denominar un acto litúrgico más que una fórmula litúrgica. Como se recordará, el Talmud ya mencionaba, en nombre de Rabi, las cuatro categorías de personas que debían pronunciar la «bendición de gratitud o alabanza» [birkat ha-gomel]. Dos de estas categorías son jurídicamente apropiadas al caso de Shem Tov de Tudela de Navarra: a) los que estaban en la cárcel y salen de ella y b) los que atraviesan el mar. Hablo de un «acto litúrgico» puesto que es evidente, tanto de la discusión talmudica como de las posteriores codificaciones jurídicas, que uno de los puntos esenciales era el hecho de difundir y hacer manifiesto en público el acto de gracias [birkat hagomel]; Esta prioridad de la publicación y difusión se expresaba en el requerimiento de que la fórmula litúrgica debía ser pronunciada frente a un minyan o quorum y dos sabios; además de la costumbre de que la congregación debe pronunciar un responsum. La publicación de agradecimiento a Dios después de pasar por este tipo de experiencias es una manera de describir el tono de la narrativa de Gamil. Si tengo razón sería casi equiparable a una especie de amplificatio, en prosa, de la fórmula litúrgica. Recuérdese también que la mayoría de las autoridades jurídicas generalmente aducidas

6 Sobre el problema de la construcción del sujeto en textos hispano-hebraicos bajomedievales ver más detalles en E. GUTWIRTH, «El exilio en primera persona: Shem Tov de Tudela de Navarra y su historia» en Actas Terceros Encuentros Judaicos (Tudela en prensa); id.; "La España de Isaac Caro", Actas IV Congreso Internacional: Encuentro de las Tres Culturas (ed. C. Carrete Parrondo) (Toledo 1988), 51-56; id.; "The Toldot Ishaq in his time" MEAH 40/2 (1991), 119-130; id. "Hebrew LettersHispanic Mails; Jewish Communications in Fourteenth Century Aragon» en ed. S. Menache, Communication in the Jewish Diaspora in the Pre-Modern Period (Leyden 1996), 257-282; id.; "Don Ishaq Abravanel and Vernacular Humanism in Fifteenth Century Iberia» B.H.R. (en prensa). 
para la codificación de este acto litúrgico están asociadas al área de Sefarad: Alfasi, Rashba, Rosh, el Tur, Ribash, etc. .

El texto de Shem Tov de Tudela por éstas y otras varias razones descuella por su eminente interés y la poca atención que se le ha prestado debe explicarse por otras causas. Es posible que haya factores de índole historiográfica. Se recordarán las duras críticas de Jacob Mann a las ediciones de fragmentos judeo-árabes de Toledano. Pero éstas no fueron extendidas a textos hispano-hebraicos. A mi parecer las dificultades de orden técnico han sido decisivas. Ante todo el problema de la ubicación del manuscrito que no llevaba sigla precisa al publicarse hace 70 años. No sería la primera vez que el progreso de la investigación acerca de un fragmento manuscrito depende precisamente de un punto técnico de este tipo. En segundo pero primordial lugar el hecho de que se trata de un fragmento manuscrito, acéfalo y truncado. En tercer lugar se puede mencionar la falta de éxito de generaciones de historiadores que no han logrado identificar definitivamente - aunque ha habido alguna que otra tentativa- las localidades, los personajes, circunstancias, ni siquiera la fecha del relato hebraico de Shem Tov de Tudela de Navarra.

En primer término está el problema de la identificación de topónimos en la crónica. El primer topónimo de la narrativa es Castelnou. Hoy en día, cuando la crítica textual ya no sigue esa tendencia decimonónica a las emendaciones radicales, no entiendo porqué es necesario emendar el texto medieval y preferir una lectura como Castellón. Castelnou no tiene nada de sorprendente como topónimo medieval. Hay más de una docena de topónimos franceses que consisten de la palabra Castelnau con alguna adición a veces. Un Castelnou, pequeño municipio que dista $8 \mathrm{kms}$. de Puebla de Hijar, corresponde a la provincia de Teruel, diócesis de Zaragoza, partido judicial de Hijar, situado en la margen derecha del río Martín que recorre el término. Más probable me parece identificarlo con Castellnou o Castelnovo, que era vecindad con ayuntamiento de la provincia de Castellón de la Plana, partido judicial y diócesis de Segorbe, audiencia territorial de Valencia situado a la izquierda del río Palancio. La villa toma su nombre del castillo arruinado en la cúspide de un monte inmediato, castillo al parecer romano, reedificado por los árabes. Las coordinadas de la narrativa del viaje de Shem Tov coinciden con la red de comunicaciones dentro de la península y la de la navegación y comercio con el norte de África. Así, por ejemplo, el Castellnou de la crónica de Shem Tov de Tudela se encuentra en el [ya entonces ${ }^{8}$ ] antiguo camino que, siguiendo el Ebro, llevaba de Tudela a Valencia. Saffi o Asfi, refugio de Shem Tov al salir de la península, era un puerto importante en la costa Oeste de Marruecos a 106 millas O.N.O. de Marrakesh. El puerto de Sale era un punto de partida para los buques musulmanes de comercio ya desde siglos atrás y en el siglo XV era conocido como destinación de los exiliados y no sorprende la mención de un viajero peningular a Sale. Tlemcen por

7 Cf. e.g. TB Ber 54b.

8 Agradezco al Prof. Hinojosa Montalvo su sugerencia acerca del camino de Tudela a Valencia. Hay que reconocer, sin embargo que en el siglo XV Castellnou no se distingue por su comunidad judía. V. J. HINOJOSA MONTALVO, The Jews of the Kingdom of Valencia (Jerusalem 1993). 
supuesto era un importante punto de referencia para los judíos de España ya por lo menos desde 1391. Es curioso, pues, notar el silencio acerca de la crónica de Shem Tov en las historias de los judíos en el Norte de África (Hirschberg, Chouraqi, etc.).

El segundo problema es el de las fechas de los sucesos en la narrativa de Shem Tov de Tudela. Una lectura del texto hebreo nos da los siguientes parámetros: se trata de una época en que el regimiento u oficio de regidor y también la cárcel de Almería están en manos cristianas. Pero se trata también de un período en el cual hay musulmanes practicantes viviendo en Almería quienes tienen poder del rey; pueden apelar a la justicia real; tienen garantías que a los musulmanes no se los encarcelará y como dice Shem Tov de Tudela de Navarra acerca de uno de ellos, Salima Elbajo «sus palabras son oídas por los cristianos por orden del rey».

Creo que a partir de estos datos que se coligen de una lectura del texto hebreo de Shem Tov de Tudela de Navarra se pueden fijar los términos cronológicos de este relato que difieren de los avanzados hasta hoy. En efecto se recordará que la campana en la zona oriental del reino de Granada comienza el 5/4/1488 desde Murcia. En diciembre de 1489 después de la entrega de Baza el 4/12, se firman las capitulaciones el día 10. Cae Almería y se firman capitulaciones con Yahia Alnayar caudillo y general de moros de Almería. El 17/12 Fernando sale de Baza a Almería. El 22 de diciembre se abren las puertas de la ciudad a Gutierre de Cárdenas y a Pedro Sarmiento, alcaide cristiano de la ciudad. El miércoles 23 entra Fernando y recibe la plaza, el jueves 24 entra Isabel y se celebra una misa en la mezquita. Los términos de las capitulaciones son famosos por ser los más generosos que se conceden. Entran bajo amparo real. Se les respetarán sus almuédanos, aljamas y alfaquies; serán juzgados por sus propios cadies, de acuerdo a su Xara y Zuna. No hay repartimiento ni repoblación. En junio de 1490 se produce una rebelión contra los castellanos. Salen partidas armadas de Almería. El marqués de Villena expulsa a los mudéjares de Guadix y luego se expulsa a los de Almería y Baza quienes deben trasladarse a Granada, a África o a lugares sin fortificar. Los mudéjares abandonan la ciudad y se inicia el repartimiento el 25/3/1491. La situación que se describe en el fragmento hebreo sin fecha de Shem Tov de Tudela de Navarra corresponde, pues, a una época entre el 24/12/1489 y a lo sumo el 25/3/14919.

Después del problema de los topónimos y las fechas, el siguiente problema es el de la identificación de los oficiales cristianos mencionados en la crónica.

La narrativa de Shem Tov de Tudela de Navarra menciona varios sarim/ oficiales cristianos, por su nombre: Don Juan de Céspedes, Juan de Salas o Sales, Pedro de Po[r]ras o Porres, Luis de Córdoba. Que yo sepa no se ha intentado identificarlos. Aquí se puede hacer lo menos una tentativa de identificación. En la crónica leemos una descripción de la experiencia de Shem Tov de Tudela de Carmona.

9 Cristina SEGURA GRAINO, Libro de repartimientos de Almeria, Madrid 1982, Introducción; Juan de MATA CARRIAZO ARROQUIA en id. y L. SUÁREZ FERNÁNDEZ, La España de los Reyes Católicos (1474-1516), Madrid 1969; M.A. LADERO QUESADA, Los mudéjares de Castilla en tiempo de Isabel I (Valladolid 1969). 
$Y$ fue a medianoche del tercer dia y llovia y en la oscuridad de la noche nos sacaron de la carcel y no sabiamos que nos pasaba. Nos sacaron encadenados como prisioneros de los reyes nuestras manos atadas por detras y llovio sobre nosotros todo el dia y toda la noche. Atravesamos un gran vado y las aguas casi nos anegaron, en resumidas cuentas el malvado [ish beliaal] nos condujo a Carmona que esta a una distancia de 40 parsaot de donde estábamos prisioneros y Carmona es muy cercana a Sevilla, una distancia de seis parsaot. $Y$ alli, en Carmona, estuvimos como prisioneros y nos pasaron muchas malas desgracias. $Y$ estuvimos bajo la mano y la autoridad del sar/oficial don Juan de Cesperes [e.d. Céspedes] y era uno de los pios de las naciones del mundo [de los gentiles] y no puedo alargar en escribir todos los sufrimientos que padecimos.

¿Quién es el «sar»/oficial Juan de Céspedes bajo cuya mano y autoridad estaban prisioneros Shem Tov de Tudela de Navarra y sus hijos en la población de Carmona cercana de Sevilla? Se trata evidentemente de un personaje de autoridad, un oficial involucrado en la guerra que tiene el poder de encarcelar o tomar prisioneros. Yo sugeriría que se puede identificar con el Juan de Céspedes mencionado en la coetánea crónica real. Se recordará que en ésta, al describir la campana contra los moros en 1485, se dice

Tomada la villa de Cartama el maestre de Santiago enbio a suplicar al Rey que por quanto aquella Orden de la caualleria de Santiago donde el era maestre fue fundada para facer guerra a los moros enemigos de la Santa Fe catolica y el estaua en proposito de seguir aquello...le plugiese darle cargo de la tenencia de aquella villa porque era dos leguas de la cibdad de Málaga e asentada en lugar dispuesto para seguir la guerra comencada ...El Rey vista la suplicacion del maestre e conocida su buena yntencion mando que se reparasen las torres e muros [...] et mandosela entregar. E el maestre la recibio e le fizo pleyto omenaje por ella e puso por alcayde en la fortaleza vn cauallero de su casa que se llamaua Juan de Cespedes... ${ }^{10}$.

No es imposible que se trate del mismo Juan de Céspedes mencionado en documento de 20/7/1491 según el cual "Juan de Cespedes regidor de Ciudad Real pide comision al corregidor sobre ciertos incidentes en la cobranza de la renta de la asadera". En 22/XI/1493 hay una comunicación «a Juan de Cespedes vecino y regidor de Ciudad Real que no conozca sin un acompanado de una causa de los oficiales de la zapateria de la ciudad que habian hecho ligas y monypodos en perjuicio de la renta de tal zapateria y del arrendador». Sin embargo me parece más probable que sea el mencionado en documento de $23 / X / 1494$, fecha en la cual se envía una «Comision a

10 (Juan de Mata Carriazo Arroquia, ed.) Hernando DEL PULGAR, Crónica de los Reyes Católicos (Madrid 1943), cap. CLXX. 
inquisidores de la provincia de Leon de la Orden de Santiago a peticion de Juan Andres vecino de Llerena quien reclama casas lindantes con las del comendador Juan de Cespedes tomadas por un alguacil de la Inquisicion sin haber causa". Y finalmente en 16/XII/1494 se manda «a [los] alcaldes del priorazgo de San Juan que determinen acerca de una deuda que quiere cobrar Alonso Pérez de San Ginés de Juan de Cespedes.»11.

Poco a poco emerge el perfil de un joven militar, Juan de Céspedes, asociado con la Orden de Santiago, involucrado en la campana de 1485, hechura o protegido del Maestre de la Orden, quien en esta época es Alonso de Cárdenas ${ }^{12}$. Después de la entrada en Cartama se le da la alcaidia al parecer con don Santo de Velasco hermano del Condestable. Años después aparece un Juan de Céspedes también como administrador pero ya los problemas son de orden civil, cuestiones de dinero, y posesiones. Similar es el problema de la identificación del "oficial y juez" mencionado por Shem Tov en relación a su hijo Isaac ben Shem Tov ibn Jamil; es decir Pedro de Porras. Es posible que se pueda identificar con el juez Pedro de Porras que aparece en documentos de la época. En efecto hay una carta sellada en 8 de febrero de 1491 dirigida al Concejo de Calahorra para que pague 15.000 maravedíes a Pero de Porras a fin de que el lugar de Villilla quede libre para la corona a la cual había pertenecido hasta que fue enajenado por 30.000 maravedíes a Diego de Zúñiga de quien pasó a Pero de Porras. Otra de 15/7/1491 también trata de tierras; dirigida al licenciado Pedro de Porras juez de residencia en la provincia de Guipúzcoa trata de un solar de Achaga en disputa. Otra más tardía del 10 de abril de 1494 se dirige a los justicias de Espinosa de los Monteros para que se cumpla el contrato entre Pedro de Porras repostero de los Reyes Católicos y el barrio de Quintanilla de Espinosa sobre la forma de llevar agua de unos molinos del concejo a otro de su propiedad ${ }^{13}$.

Finalmente se puede señalar, en relación al Luis de Córdoba que menciona Shem Tov, que hay una carta sellada el 22 de noviembre de 1494 dirigida a los justicias de Lucena y Écija para que Fernando de Palma vecino de Écija y mercader de panos abone a Luis de Córdoba, vecino de Córdoba unos paños que le dio fiados ${ }^{14}$.

En conclusión, no he exhaustado todos los problemas que presenta la crónica pero he tratado de sugerir algunos de ellos y proponer unas metodologías para solucionarlos.

11 Acerca de Céspedes [la confusión entre resh y dalet es fácil de explicar paleográficamente]. V. AGS, RGS, Catálogo, t. 8, ํo 1944, t. 10; nº 2.994; t. 11; nº 3.412; 3.870; 4.373 .

12 V. la Consolatoria de Castilla de Juan Barba, CCVI y las notas de su editor P.M. Catedra, La historiografia en verso en la época de los Reyes Católicos (Salamanca 1989), p. 236.

13 Sobre Pedro de Porras v. RGS, t. 8, nº 328; 1913; t. 9, n² 2.047; t. 11, nº 1.170. En julio de 1490 se asocia a Pedro Porras con la región pertinente: RGS t. $7, n^{\circ} 2.486$ es una carta a favor de Pedro de Porras y su mujer Ana Pineda vecinos de Córdoba para que se les pague el arrendamiento de un heredamiento.

14 Sobre Luis de Córdoba v. ib. t. $7 ; n^{\circ} 3.220 ; t .11$, no 1.108; 3.952; v. también t. 9, $n^{\circ} 1.312$ sellado en 30/4/1492; donde se menciona el pleito del Monasterio de Santa Inés de Córdoba contra doña Leonor Ponce de León, mujer de Luis de Córdoba cuya fue la villa de Guadalcázar. 


\section{TRADUCCIÓN}

[...] y en ese mismo tiempo enviaron por mi hijo a Castellnou. Su intención era robar y saquear y cometer pillaje en mi trabajo que se encontraba allí. Y Dios guarda a los tontos y despertó el espíritu de mis hijos y Dios no permitió que le hicieran daño. $Y$ cada cual huyó a lugares diferentes. Y cuando vieron que no consiguieron su propósito acudieron a la casa y todo el trabajo fue robado y destruido y expropiado. $Y$ después de tres semanas de estar en la prisión de Valencia en el Sabat en que viene el descanso enviaron por mí los padres de la impureza. $Y$ me dijeron: ¿qué haces aquí y a quién tienes aquí? esta prisión será tu tumba. Levántate y confiesa en nombre de nuestro error [e.d. conviértete al cristianismo] y seremos piadosos contigo. $Y$ si no lo haces, morirás. Porque esta es la orden del Rey. Y entonces dije: soy anciano y no sé cual es el día de mi muerte. Como puedo responderos si estoy tan confundido. Dadme tiempo y os daré una respuesta. Y ellos dijeron que así sea como tú dices pero vuelve a la prisión. Y entonces les dije: ¿porque dicen eso sus Altezas?; es que así es la costumbre de las aguas amargas [e.d. del bautismo]? ¿bautizarse saliendo de la cárcel? $Y$ entonces dijeron está bien. $Y$ bendije al Señor quien me aconsejó; quien me puso en el camino de la verdad. Y cuando el sol comenzó a volver a su casa, al final del Sabbat tomé un joven musulmán, y le di su pago y me sacó de ese malvado lugar. Y me llevó a un pueblo cerca de Valencia. Y a medianoche tomé otro joven musulmán y le di su paga y me trajo durante la noche a las cercanías de Castelnou e investigué acerca de mi hijo y de mi trabajo [fortuna] y los encontré en diferentes lugares. $Y$ en ese momento no sabíamos lo que hacer. Era un tiempo de angustia, sólo en Dios teníamos esperanza. $Y$ decidimos ir hacia Tortosa para ver si podíamos embarcarnos a la mar porque era puerto de embarque. Pero no lo logramos. Y nos tornamos a medio camino pues en todo lugar donde nos veían la gente se levantaba contra nosotros, diciendo: estos son los judíos que buscan los padres de la impureza para quemarlos en el fuego. Y con todo decidimos ir hacia Almería, que está en el reino de Granada. Nos dijeron que ese era lugar donde nos podíamos salvar embarcándonos de noche para Orán, que es un lugar cercano a Tlemcen. E hicimos lo que habíamos decidido, a pesar de que el camino era largo, más de 100 parsaot $^{15}$. Aparte de esto teníamos que pasar por Valencia, el lugar donde nos estaban buscando con una gran investigación [o inquisición]. Y el día que pasamos por ahí —Valencia- Dios con su piedad creó un gran alboroto en la ciudad. Y nos salvamos y Dios nos salvó y llegamos allí con paz y tranquilidad y seguridad no hay adversario ni mal que temer. Y llegó el día y salimos alli en Almería a ver las olas del mar y sus mareas y vino el Satán y dijo: ¿de dónde sois? habeis venido a espiar y le dijimos: no Señor; tus siervos han venido a ver si podemos pasar por barco a Tlemcen donde tenemos parientes desde hace mucho tiempo. Y nos dijo: no, sois judíos y se os nota en la cara y envió su mano y nos

15 La parsa talmúdica equivale a $32 / 5$ de la milla inglesa, alrededor de $5 \mathrm{~km}$. Así los $30 \mathrm{~km}$. de Sevilla a Carmona se convierten en 6 parsaot. El "gran vado" puede que sea una referencia al Guadalhorce más que el Cordones, Blanco u Peinado. 
llevó presos al regidor de la ciudad. Y nos tiraron a la prisión encadenados con hierro y cautivos de la miseria. $Y$ en ese mismo lugar había un musulmán honorable y sus palabras eran oídas por los oficiales de los gentiles [cristianos] porque esa era la orden del rey. Y cuando oyó esto, se enojó y les dijo: ¿porqué habeis hecho esto?; esta gente es musulmana y hace tiempo que los conozco a ellos y a sus familias. $Y$ esos malvados gentiles endurecieron sus caras como una roca y dijeron: son judíos y buscaron muchas razones, estratagemas y trucos y no le creyeron. $Y$ el honorable musulmán se llamaba Salima el Bajo y volvió a presentar su petición y dijo: saquen a esta gente del calabozo y si no, por la verdad y por la fe, que voy a ir a los reyes por mi cuenta y les diré la justicia y la rectitud de esta gente y veremos quien ganará el juicio, yo o vosotros. $Y$ entonces el regidor de la ciudad respondió: si la verdad es con ellos, que son ishmaelitas, que digan la oración que vosotros acostumbrais rezar. Y el musulmán respondió: que sea como vosotros dijísteis. Y entonces nos sacaron de la prisión y cada uno de nosotros dijo su oración sin ningún error y sin ninguna falta y entonces se derrumbaron sus argumentos. Y entonces, cuando Dios nos mostró su mano y su fortaleza y nos sacó de las tinieblas a la luz decidimos ir a Granada para buscar hogar en que nos vaya bien [Cf. Rut 3/1] puesto que no podíamos atravesar la mar por barco desde Almería. $Y$ allí estuvimos cuatro meses. $Y$ después de cuatro meses se vio una caravana de cien personas, hombres con familias, que querían pasar a Fez y dijimos venid y caminaremos a la luz de Dios [cf Is. 2/5]. Y no me dilataré relatando las grandes y terribles pruebas que nos ocurrieron, pero en general, allí en el lugar de Granada nos ideron permiso y pagamos 30 ducados ${ }^{16}$ de impuesto. $Y$ cuando Dios nos movió de Granada llegamos a Vélez Málaga. Y un hombre infame nos delató diciendo que éramos judíos. $Y$ no podré alargar toda los sufrimientos que padecimos allí. En general nos apresaron y nos pusieron en la cárcel a nosotros y a nuestros asnos y todo lo que teníamos. $Y$ esta fue la peor tribulación de todas. Y allí estuvimos dos días y una noche. $Y$ fueron extremadamente malvados con los musulmanes que iban con nosotros, diciendo que ellos estaban al tanto.

Y fue a medianoche del tercer día y llovía y en la oscuridad de la noche nos sacaron de la cárcel y no sabíamos que nos pasaba. Nos sacaron encadenados como prisioneros de los reyes nuestras manos atadas por detrás y llovió sobre nosotros todo el día y toda la noche. Atravesamos un gran vado y las aguas casi nos anegaron [Ps 124/4] en resumidas cuentas el malvado [ish beliaal] nos condujo a Carmona que está a una distancia de 40 parsaot de donde estábamos prisioneros y Carmona es muy cercana a Sevilla, una distancia de seis parsaot. $Y$ allí, en Carmona, estuvimos como prisioneros y nos pasaron muchas malas desgracias. $Y$ estuvimos bajo la mano y la autoridad del sar/oficial don Juan de Cesperes [e.d. Cespedes] y era uno de los píos de las naciones del mundo [de los gentiles] y no puedo alargar en escribir todos los sufrimientos que padecimos. Nos decían todo el día que dejemos al Dios vivo y estuvimos así cuatro meses. $Y$ después que pasaron cuatro meses los reyes mandaron

16 Shem Tov no precisa si se refiere a los ducados de Venecia o a otros como ser por ejemplo al de Valencia, equivalente al medio excelente. 
[una orden diciendo que] nos devuelvan al lugar en el cual nos aprehendieron y ese es el lugar de Vélez Málaga y allí los reyes decidirian que es lo que harían. Y estuvimos allí durante dos meses y medio en la cárcel y aquí pondré fin a mis palabras y no alargaré en las vicisitudes que nos ocurrieron. No pueden ser enumeradas. [Ps, 40/6: tus pensamientos... si yo anunciare y hablare de ellos, no pueden ser enumerados...] $Y$ después de dos meses y medio el rey mandó por nosotros que nos condujeran al lugar Granada el lugar donde estábamos al principio y le dieron todo lo que nos habian quitado 30 litras de seda ${ }^{17}$ y 14 monedas de oro bueno. $Y$ estuvimos allí en la prisión un mes y después de haber pasado el mes se llevaron a mis dos hijos pequeños [cf Ez 24/21] el deleite y deseo de mi alma Josue y Ya'aqov llamados ben Gamil. $Y$ los gentiles los tornaron contra su ira y enojo [cf p.ej.Jer. 32/31] y nos amenazaron con las cuatro [formas de] muerte judicial [cf. Sanh VIII/1; TB Sot 8b]. Y cuando vieron que su voluntad no se cumplía nos regalaron a tres oficiales para que hagan su voluntad.

Y a pesar de todo esto no olvidamos el nombre de nuestro Dios ni extendimos nuestras palmas [en rezo cf. Ex 9/29] a un dios extraño. Y a mí el anciano me tocó caer en manos de un hombre que se llamaba Juan de Salas. $Y$ esa persona era uno de los píos de las naciones de los gentiles a pesar de ser joven. $Y$ a poco de caer en sus manos me pasé al lugar de Safi [o Asfi en Marruecos] por barco en el corazón del mar. $Y$ allí vi la obra de Dios: tres veces entré y salí del mar porque el mar estaba tormentoso y a la cuarta entramos en paz y salimos en paz. $Y$ dos judíos probos y justos de allí nos redimieron y dieron 50 onzas de plata en un espacio de tres días. Que el Pagador les pague sus esfuerzos y que su pago sea completo. Y en [la semana en que se lee] el pericopio [Gn 42/18; e.d. Miqes] «Haced esto y vivid. Yo temo a Dios» prediqué palabras de Torah y el tema que elegí fue [Gn. 43/14] «El Dios Omnipotente os dé misericordia".

$Y$ allí viví durante tres meses o más para averiguar y buscar a mis hijos del Dios viviente, Isaac y Samuel [ib]n Gamil que quedaron en manos de sus señores. $Y$ se averiguó el asunto y se encontró que mi hijo primogénito, el inteligente y escriba cayó su destino en manos del oficial y juez Pedro de Pores [o Porras?] y él también era de los píos de las naciones del mundo. Y el nombre del hombre que le fue destinado a mi hijo querido mi selecto, quiero decir al prudente y escriba, su hermano, que se llama Samuel ben Gamil, era un hombre perverso [de beliaal] se llamaba naval [infame] y era un nevelah [infamia o carrona] y Dios dedició que este hombre lo vendiera a un oficial honorable llamado Luis de Córdoba y él también era de los píos de las naciones del mundo. Y el Nombre Bendito sea al que se le dieron aptitudes el que es grande de consejo y grande de tramas quien desde su trono guarda a todas las criaturas por la súplica y los ruegos de mi dicho hijo Samuel el Señor fue celoso por él. Y cuan bueno y cuan delicioso es habitar los hermanos juntos en armonía no serán separa-

17 Sorprende un poco el uso de esta medida para telas (más que otras como ser el codo) aunque dentro de la práctica alusiva de Shem Tov tiene su lógica. La litra talmúdica [cf. p. ej. TB, BB 89a] equivale a la libra romana de 12 unciae. 
dos y allí habitaron durante tres años [trabajando] con barro y ladrillo toda labor del campo y todo el trabajo en el que trabajaron forzados [cf. Ex. 1/14: «y amargaron su vida con dura servidumbre en hacer barro y ladrillo y en toda labor del campo y en todo su servicio al cual los obligaban con rigor")].

Y durante esos tres años no supe nada acerca de ellos. Y ellos tampoco sabían nada de mí. Y estábamos como entre la vida y la muerte hasta que Dios observó desde el cielo y miró y vino un comerciante por barco a través del corazón del mar al lugar Sale [Marruecos]. Y los judíos probos le dieron mil maravedies por contratos [letras de cambio?] de mi mano y parte para que los lleve al señor Luis de Córdoba bajo cuya mano estaban [mis hijos] y he aquí que el [e.d. Luis de Córdoba] pedía doscientos ducados por su rescate, ni más ni menos. Y se mandaron los dichos contratos [letras de cambio] al lugar Alcázar [Marruecos] puesto que allí viví durante nueve meses todo ojos que esperaban a mi Dios. Y entonces cuando oí la buena noticia, la buena nueva conforta los huesos, mi corazón se llenó por venir con las letras de cambio a las comunidades felices de Fez porque allí ordenó Dios [Ps 133/3 como rocío de Hermon que desciende sobre los montes de Sion Porque allí envía Dios] bendición y vida eterna [oh morada de justicia oh monte santo] durante [la semana en que se lee] el pericopio [Ki Tese'; Dt 23/15] «Tu Dios anda en medio de tu campamento para librarte» y entonces cuando los sabios y jefes del pueblo oyeron las buenas nuevas los generosos de los pueblos se juntaron con el Dios de Abraham. Y estaban de acuerdo en que vaya a Tlemcen al príncipe/nagid corona y ornamento de Israel un hombre perfecto y derecho que teme a Dios y se aparta del mal. Y allí también se juntaron los generosos del pueblo. $Y$ el aludido príncipe generoso hizo generosidades.

$Y$ el Señor me condujo por el sendero de la verdad y a pesar de que los caminos eran peligrosos y está a una distancia de alrededor de 120 parsaot y hay pocos caminos [o caravanas] y pocos viajeros y el Señor de los ejércitos me condujo por el verdadero camino y llegué allí en el pericopio Gn 18/19 «Guarda el camino de Dios haciendo justicia y verdad" y allí enseñé palabras a Torah y comencé con este versículo y allí me dieron veinte doblas...

18 La mención por Shem Tov de las veinte doblás como pago por un sermón en Tlemcen se entiende si recordamos la importancia de las doblás de los moros de los estados berberes en la historia monetaria de p. ej. Valencia y su mención en documentación valenciana del siglo XV; v. E.J. Hamilton, Money Prices and Wages in Valencia, Aragon and Navarre, (Cambridge 1936), p. 17, no 4. Recuérdese también que es la doblá granadina la que sirve de modelo para la doblá de la banda v. p. ej. M.A. LADERO, El siglo XV en Castilla (Barcelona 1982), p. 118 ss. 